\title{
Evaluation of Balance Test Outcomes in Children with Poor Vision
}

\author{
Banu Baș (1), Mustafa Karabulut (i), Banu Müjdeci (i) \\ Department of Audiology, Ankara Yıldırım Beyazıt University, School of Health Sciences, Ankara, Turkey
}

ORCID iDs of the authors: B.B. 0000-0002-252I-4545; M.K. 0000-0002-6149-3967; B.M. 0000-0002-3660-3650.

Cite this article as: Baș B, Karabulut M, Müjdeci B. Evaluation of Balance Test Outcomes in Children with Poor Vision. Cyprus J Med Sci 2020; 5(4): 284-8.

\section{BACKGROUND/AIMS}

Balance is constituted through the integration of vestibular, proprioceptive, and visual and motor neurophysiology systems. Any discrepancies in any one of these systems may negatively influence the overall balance and postural stability. This study aimed to evaluate balance in children with poor vision.

\section{MATERIAL and METHODS}

The subjects of the present study were children with poor vision. The mean age of the children in the study group $(n=20)$ was $7.35 \pm 1.92$ years, while that of the children in the control group with healthy vision was 8.2 1.10 years. All subjects were assessed with the Functional Reach Test, Romberg Test, Single Leg Stance Test (eyes open and closed), Pediatric Berg Balance Scale (PBBS), Modified Clinical Test of Sensory Interaction on Balance (mCTSIB), and The Timed Up $\delta$ Go (TUG) Test.

\section{RESULTS}

The results showed that children with poor vision performed relatively poorer than healthy children in the Functional Reach Test, Romberg Test, Single Leg Stance Test (eyes open and closed), PBBS, mCSTIB, and TUG tests ( $p=0.00$ ). We noted that children with poor vision had to strain more to preserve their postural stability in the Single Leg Stance Tests and the mCSTIB Test with closed eyes relative to that with opened eyes $(p=0.00)$.

\section{CONCLUSION}

Our findings indicate that children with poor vision have weaker balance relative to their healthy peers. Thus, inadequate level of visual input negatively influences the body balance in children.

Keywords: Vision, low, balance, children

\section{INTRODUCTION}

Balance is constituted through the integration of the vestibular, proprioceptive, and visual system. Since children's first interactions with their environment occur through a sense of touching and vision, it is crucial for children to develop and maintenance their balance skills. Any discrepancies in any one of these systems may negatively impact the overall balance and postural stability in an individual (I).

Past studies have reported that vision is pivotal in terms of the preservation of postural stability (2-4). It has been proposed that the decrease in the postural stability increases the risk of fall in individuals with poor vision $(5,6)$.

According to the World Health Organization (WHO) (6), poor vision is defined as visual acuity of $<6 / 18$ but $\geq 3 / 60$ or a corresponding visual field loss of $<20^{\circ}$, in the better eye with the best possible correction (ICD-I0 visual impairment categories I and 2) (6,7). Poor vision may be congenital or hereditary and reflect the situation in which vision cannot be repaired with the help of glasses, contact lenses, and medical or surgical treatments. Individuals with poor vision utilize from the vestibular and proprioceptive systems more in order to compensate for their visual dysfunctions (6).

It is already known that vision plays a dominant role in the process of coding and maintenance of other sensory information. It has been discovered that, when healthy and visually impaired subjects are evaluated in accordance with eyesclosed experiments, the stability is decreased and other sensory inputs cannot completely compensate for the visual 
inputs $(3,8)$. Whether poor vision is congenital or hereditary is also crucial for determining the balance (9).

Some past studies have compared the balance scores of visually impaired and healthy individuals $(5,9)$, and only a limited number of studies compared the balance scores between healthy individuals and individuals with low vision $(3,5,10)$. These studies especially indicate that single-leg stance on a foam surface with eyes opened and closed increases the postural instability and body sway $(5,11)$.

The aim of the present study was to evaluate balance in children with poor vision.

\section{MATERIAL and METHODS}

The study was approved by Ankara Yıldırım Beyazıt University ethics committee with the date / decision no of 25.10.2017 / 02. The data collection process was initiated after ethical consent. Verbal and written information was given to the children and parents about the purpose and scope of the study, and their written consent was obtained.

\section{Participants}

We first ensured that the inclusion of 20 children each in the study and control groups was suitable for statistical evaluation. The study included 20 children with congenital poor vision of mean age $7.35 \pm 1.92$ years (study group) and 20 children with healthy vision of mean age $8.20 \pm 1.10$ years. The ethical committee approval was received for this study. Written permissions from the subjects' families were received. The inclusion criteria for the participants were determined as follows: having no hearing loss, being able to receive commands, being able to walk without help for $10 \mathrm{~m}$, having no additional impairment, and having no neurological or vestibular system issues. In addition, for the study group, an intensive visual evaluation was conducted by ophthalmologists (e.g., vision loss screen tests, optimal visual acuity test, and ophthalmological examination), and the criteria for poor vision was established in accordance with the WHO specifications for participation. In the control group, children with no history of vision loss and with 20/20 rations in the Snellen eye chart (who could answer correctly for E's in 40 - 20 feet line).

\section{Methods}

All children were evaluated with the Functional Reach Test, Romberg Test, Single Leg Stance Test (eyes open and closed), Pediatric Berg Balance Scale (PBBS), Modified Clinical Test of Sensory Interaction on Balance (mCTSIB), and The Timed Up $\bar{d}$ Go (TUG) Test. Although the evaluation of each child varied with respect to their physical traits, the evaluations lasted for I and half hours, which included the resting breaks. There were

\section{Main Points:}

- Visual inputs are important for balance.

- Children with low vision may fail to maintain postural control in difficult conditions.

- Early detection of imbalance with balance assessment in children with low vision is important in preventing possible falls. resting sessions of $10-15$ min between each tests considering the children's needs. All tests were applied on the same day with adequate breaks between them. The necessary safety precautions against falling hazard throughout the evaluation process were practiced. In order to maximize the performance of children with poor vision, the necessary adjustments (e.g., walking path with contrasting colors, lightings on the finish lines) were already done for the tests. All tests were performed by the same specialist audiologist at the special education and rehabilitation center.

\section{Functional Reach Test}

The Functional Reach Test is used to evaluate both balance and the dynamic reach value. Initially, the children were asked to point their arms in front of them in a straight line, and the reach value was recorded. Then, they were asked to lean forward without lifting their heels and the maximum distance, to which the children could lean forward and back without losing their balance, was recorded (12).

\section{Romberg test}

Romberg Test is a neurological function test that evaluates the integrity among different sensory organs and neuronal conduction pathways utilized in the maintenance of balance. The test offers information about the central and peripheral vestibular system function and peripheral proprioception. Children were asked to stand upwards for $30 \mathrm{~s}$ with their eyes closed in this test $(13,14)$

\section{Single Leg Stance Test}

In this test, the vestibular function and proprioception sense were evaluated. The participants were asked to lift their one leg without touching the other and wait for $30 \mathrm{~s}$ in that posture, initially with their eyes opened and then with eyes closed. The test was terminated in cases in which the lifted leg touched the ground or the other leg or skipping, hopping, or grabbing of the surrounding objects in order to maintain balance was noted (I5).

\section{Modified Clinical Test of Sensory Interaction on Balance (mCTSIB)}

This test was used to evaluate the sensory system dysfunction on a firm and foam surface, with both eyes opened and closed. In tests on the foam surface with eyes closed, the effects of visual and somatosensory inputs were eliminated and the effects of vestibular inputs on postural stability were evaluated more efficiently. In the test, the children were asked to preserve their balance in 4 different conditions: I. Eyes opened, on a firm surface, 2. Eyes closed, on a firm surface, 3. Eyes opened, on the foam surface, and 4. Eyes closed, on the foam surface, and the maximum time values for which the children could manage to stand in balance were recorded (16).

\section{The Timed Up and Go Test [TUG]}

This test is a conveniently applicable and reliable test used to evaluate the functional mobility and balance. Different variables such as the walking speed, postural control, functional mobility, and balance were evaluated in this test (I7). In this test, the participants were first seated on a chair and then asked to stand up without handling the grip, walk for $3 \mathrm{~m}$, and then sit again. During this task, the observers recorded the time with a chronometer. 


\section{Pediatric Berg Balance Scale [PBBS]}

PBBS is a highly valid and reliable test used to evaluate the functional balance in routine life activities. It is the pediatric version of the Berg Balance Scale developed by Franjoine et al. (18). The highest point was 56 on the scale, which consisted of 14 sections and it was evaluated between 0 and 4 . These sections were designed to have increasing functional difficulty levels. In the PBBS, the overall scores were recorded. On the PBBS scale, the overall score of $0-20$ was considered as a balance disorder, while the score of 2l-40 was considered as an acceptable balance performance and $4 \mid-56$ corresponded to a good performance (I8).

\section{Statistical Analysis}

Statistical analyses were performed using the Statistical Package for Social Sciences software version 18 (IBM SPSS Corp.; Armonk, NY, USA). The compatibility of the data with respect to the normal distribution was evaluated with histograms, probability plots, and Kolmogorov Smirnov/Shapiro-Wilk's test. For every balance test and age variant between the groups, the valves of mean \pm standard deviation were used. In a comparison of all test results between the groups and independent t-test were used. The paired t-test was used to compare the test scores of single-leg stance test and mCTSIB between the eyes open and eyes closed test conditions. $p<0.05$ was considered to be statistically significant.

\section{RESULTS}

The results of the Single Leg Stance Test, Romberg Test, mCTSIB, and Functional Reach Test are depicted in Table I. In all these tests, children with poor vision could only maintain their balance for a relatively short duration $(p=0.00)$.

In the Romberg test, the mean duration for which the children with poor vision managed to maintain their balance was determined to be $27.65 \pm 5.82 \mathrm{~s}$. In the control group, all children with healthy vision managed to complete the task in $30 \mathrm{~s}$. Between the two groups, no statistically significant difference in terms of the Romberg Test scores were noted ( $p=0.08$; Table I).

In the TUG test, children with poor vision completed the walking task in a greater amount of time relative to that by the control children ( $p=0.00$; Table 2).

The overall PBBS score was relatively lower for the children with poor vision than for the control children ( $p=0.00$; Table 2).

In both the children with poor and healthy visions, the performance in the Single Leg Stance test was found to be better when the test was conducted in 'eyes opened' position ( $p=0.00)$. In the mCTSIB test on children with poor vision, it was determined that children performed better in 'eyes opened' position with respect to 'eyes closed position on firm and foam surfaces $(p=0.00)$. The children in the control group managed to reach the maximum time interval of 30 s on both firm and foam surfaces in the mCTSIB test (Table 3).

\section{DISCUSSION}

In the present study, children with poor vision performed poorly in the vestibulospinal tests. External stimuli and motor development played a significant role in terms of the development of postural control among the children. The fact that there was not

\begin{tabular}{|c|c|c|c|}
\hline Test & $\begin{array}{l}\text { Study Group } \\
\text { Mean } \pm S D\end{array}$ & $\begin{array}{c}\text { Control Group } \\
\text { Mean } \pm \text { SD }\end{array}$ & $\mathbf{p}$ \\
\hline Romberg Test-EC (sec) & $27.65 \pm 5.82$ & $30.00 \pm 0.00$ & 0.08 \\
\hline Single Leg Stance-EO (sec) & $5.64 \pm 2.66$ & $20.88 \pm 1.33$ & $0.00^{*}$ \\
\hline Single Leg Stance-EC (sec) & $2.16 \pm 0.77$ & $9.72 \pm 1.13$ & $0.00^{*}$ \\
\hline mCSTIB (firm surface-EO) (sec) & $26.45 \pm 5.39$ & $30.00 \pm 0.00$ & $0.00^{*}$ \\
\hline mCSTIB (firm surface-EC) (sec) & $20.45 \pm 6.15$ & $30.00 \pm 0.00$ & $0.00^{*}$ \\
\hline mCSTIB (foam surface-EO) (sec) & $24.30 \pm 4.49$ & $30.00 \pm 0.00$ & $0.00^{*}$ \\
\hline mCSTIB (foam surface-EC) (sec) & $15.50 \pm 6.61$ & $30.00 \pm 0.00$ & $0.00^{*}$ \\
\hline Functional Reach Test $(\mathrm{cm})$ & $24.65 \pm 7.30$ & $33.15 \pm 1.98$ & $0.00^{*}$ \\
\hline
\end{tabular}

\begin{tabular}{|c|c|c|c|}
\hline Test & $\begin{array}{c}\text { Study Group } \\
\text { Mean } \pm S D\end{array}$ & $\begin{array}{c}\text { Control Group } \\
\text { Mean } \pm S D\end{array}$ & $\mathbf{p}$ \\
\hline TUG (sec) & $22.43 \pm 7.80$ & $9.82 \pm 1.00$ & $0.00^{*}$ \\
\hline PBBS (score) & $42.90 \pm 9.90$ & $56.00 \pm 0.00$ & $0.00^{*}$ \\
\hline
\end{tabular}

*p $<0.05$, independent t-test. TUG: Time Up $\bar{\alpha}$ Go test, PBBS: Pediatric Berg Balance Scale

TABLE 3. Comparison of Eyes Opened and Eyes Closed Scores of Single Leg Stance Test and Modified Clinical Test of Sensory Interaction on Balance

\begin{tabular}{|c|c|c|c|}
\hline & \multicolumn{3}{|c|}{ STUDY GROUP } \\
\hline & EO Mean $\pm S D$ & EC Mean $\pm S D$ & p \\
\hline Single Leg Stance (sec) & $5.64 \pm 2.66$ & $2.16 \pm 0.77$ & $0.00^{*}$ \\
\hline mCSTIB (firm surface) (sec) & $26.45 \pm 5.39$ & $20.45 \pm 6.15$ & $0.00^{*}$ \\
\hline \multirow[t]{3}{*}{ mCSTIB (foam surface) (sec) } & $24.30 \pm 4.49$ & $15.50 \pm 6.6 \mid$ & $0.00^{*}$ \\
\hline & \multicolumn{3}{|c|}{ CONTROL GROUP } \\
\hline & EO Mean \pm SD & EC Mean $\pm S D$ & $p$ \\
\hline Single Leg Stance (sec) & $20.88 \pm 1.33$ & $9.72 \pm 1.13$ & $0.00^{*}$ \\
\hline mCSTIB (firm surface) (sec) & $30.00 \pm 0.00$ & $30.00 \pm 0.00$ & - \\
\hline mCSTIB (foam surface) (sec) & $30.00 \pm 0.00$ & $30.00 \pm 0.00$ & - \\
\hline
\end{tabular}

${ }^{*} p<0.05$, paired t-test. mCTSIB: Modified Clinical Test of Sensory Interaction on Balance, EO: Eyes Opened, EC: Eyes Closed

adequate visual input for the children with poor vision negatively affected the extent of external stimuli and motor development (6).

Balance was maintained with respect to the visual, proprioceptive, vestibular, and motor development systems. The fact that there was no or insufficient amount of visual stimuli for children with poor vision negatively affected the ability to control the postural stability.

Several past studies have emphasized that vision impairment decreases postural stability $(3,5,7,11)$. In our study, we determined that children with poor vision showed decreased postur- 
al stability in the Single Leg Stance, mCTSIB, Functional Reach Test, PBBS, and TUG tests, which conforms to the findings of previous studies.

The fact that it is relatively harder to maintain balance without vision indicates that the balance control mechanisms are mostly dependent on vision (7, II, 19). Kayıhan et al. (20) analyzed the balance and touch perception. In their study, 29 visually impaired children and 41 children with low vision of ages II-20 years were compared to 40 children with healthy vision of ages $16,17,18$. The cumulative results of this study indicated that children with healthy vision had longer Single Leg Stance time. In addition, researches determined that the inefficiency of a vision-balance mechanism negatively affected the coordination activities (20,21). In children with poor vision in our study, the duration of postural stability was determined to be shorter relative to those of children with healthy vision; this finding coincides with that of previous studies. Moreover, our study revealed a significant difference between the results with "eyes opened" position and "eyes closed" position for children with poor vision. Furthermore, in mCTSIB tests, in the "eyes closed" position on both firm and foam surfaces, this time interval was relatively shorter in children with poor vision. The balance control on a single-leg stance was mostly dependent on the visual information. In challenging positions, the proprioceptive input decreased and, in this case, the visual and vestibular inputs became more significant. Considering that children with poor vision received lesser amount of visual input, only vestibular input was utilized to maintain the postural control, and the overall performance of the children in terms of postural stability was negatively affected (II). This finding illustrates whether the tests were conducted with opened or closed eyes and whether the surface texture had a meaningful impact on the balance scores of the study group. This conclusion can be explained by the fact that visual proprioceptive information was relatively more sensitive than mechanic proprioceptive information, which was received from the vestibular and somatosensory systems $(5,9)$. In children with hereditary poor vision, all stages of motor development were improved through exploration of the environment. Since significant motor skills were already established in cases with congenital poor vision, it is possible to plan and manipulate actions accordingly (6). We believe that disruptions in the balance scores in challenging positions can be explained in comparison to the fact that the participants in our study group had hereditary poor vision; thus, they were unable to adapt to these positions. In our study, the finding that children with hereditary poor vision performed relatively poorer in the balance action on foam surface and in "eyes closed" position may indicate the necessity of familiarity and adaptation in terms of postural control in the proprioceptive and vestibular systems $(5,9)$.

Kayihan (22) emphasized that visually impaired children required more experience in their routine life due to the delay in the development of motor skills. Bauchard et al. (23) compared 30 visually impaired children with 30 healthy-vision children of ages 8-13 years and concluded that visually impaired children had relatively poorer motor skill development. Murphy and O'driscoll (24) evaluated the factors of speed, agility, balance, and coordination skills in 6 visually impaired children of ages 5-6 years for over 2 years. At the end of their study, they noted issues in the visually impaired children in terms of these skills.
Piereira (2l) indicated that when individuals with healthy vision and visually impaired individuals of the same age were compared with respect to their overall performance in balance control, the latter group performed relatively poorly. In our study, the overall completion time of the TUG test was determined to be longer for children with poor vision when compared with those in the control group, which conforms to the findings of previous studies $(8,21,22)$. The poorer performance of the study group in the TUG test with respect to the control group can be explained based the delay in the development of their motor skills (18), weaknesses in their motor skills (6), and disruptions in the speed, agility, balance, and coordination skills (24).

In the past studies, PBBS was often used to evaluate the balance performance in sitting and standing stance and the functional balance. In our study, a meaningful difference was noted between the study and control group in terms of the PBBS scores. Despite this difference, the average overall scores of both the study and control groups correspond to a "good balance" score. This result indicated that the study children in our study could perform independently in their routine activities with respect to their current visual condition. Together with this idea, we determined that the balance control in children with poor vision was negatively affected by challenging conditions such as the foam surface or "eyes closed" position in the Single Leg Stance Test, $\mathrm{mCSTIB}$, and Functional Reach Test owing to the inefficient visual input. This finding implies that children with poor vision were more susceptible to the falling hazard in the challenges presented in everyday situations (soft ground, inclined ground, and dark or dimmed environment). We believe that this conclusion can be applied as a policy-determining factor in terms of the fall-prevention strategies against falling hazard among children with poor vision and in rehabilitation programs that aim to increase the vestibular adaptation.

Ethics Committee Approval: Ethics committee approval was received for this study from the ethics committee of Ankara Yıldırım Beyazıt University (25.10.2017/02).

Informed Consent: Written informed consent was obtained from patients who participated in this study.

Peer-review: Externally peer-reviewed.

Author contributions: Concept - B.B.; Design - B.B.; Supervision - B.M.; Resource - B.B., M.K.; Materials - B.B., B.M.; Data Collection and/or Processing - B.B., M.K.; Analysis and/or Interpretation - B.M.; Literature Search - B.B., M.K.; Writing - B.B.; Critical Reviews - B.M.

Conflict of Interest: Authors have no conflicts of interest to declare.

Financial Disclosure: The authors declared that this study has received no financial support.

\section{REFERENCES}

I. McLeod B, Hansen E. Effects of the Eyerobics Visual Skills Training Program on Static Balance Performance of Male and Female Subjects. Perceptual and Motor Skills 1989; 69(3_suppl): II23-6. [Crossref]

2. Hsu WL, Scholz JP, Scho'ner G, Jeka JJ, Kiemel T. Control and estimation of posture during quite stance depends on multijoint coordination. Journal of Neurophysiology 2007; 97(4): 3024-35. [Crossref]

3. Giagazoglou P, Amiridis IG, Zafeirids A, Thimara M, Kouvelioti $V$ Kellis E. Static balance control and lower limb strength in blind and 
sighted women. European Journal of Applied Physiology 2009; 107(5): 57|-9. [Crossref]

4. Choy NL, Braver S, Nitz J. Changes in postural stability in women aged 20 to 80 years. J Gerontol A Biol Sci Med Sci 2003; 58(6): 52530. [Crossref]

5. Schmid M, Nardone A, De Nunzio AM, Schmid M, Scleppati M. Equilibruim during static and dynamic tasks in blind subjects: no evidence of cross-modal plasticity. Brain 2007; 130(P+8): 2097-107. [Crossref]

6. Atasavun Uysal S, Düger T. A comparison of motor skills in Turkish children with different visual acuity. Fizyoterapi ve Rehabilitasyon Dergisi 20ll; 22(I): 23-9.

7. Tomomitsu MS, Alonso AC, Morimoto E, Bobbio TG, Greve JM. Static and Dynamic postural control in low-vision and normal-vision adults. Clinics 2013; 68(4): 517-21. [Crossref]

8. Schieppati M, Tacchini E, Nardone A, Tarantola J, Corna S. Subjective perception of body sway. J Neurol Neurosurg Psychiatry 1999; 66(3): 313-22. [Crossref]

9. Friedrich M, Grein HJ, Wicher C, Schuetze J, Mueller A, Lavenroth A, et al. Influence of pathologic and simulated visual dysfunctions on the postural system. Exp Brain Res 2008; 186(2): 305-14. [Crossref]

10. Ray Ct, Horvat M, Croce R, Mason RC, Wolf SL. The impact of vision loss on pustural stability and balance strategies in individuals with profound vision loss. Gait Posture 2008; 28(I): 58-61. [Crossref]

II. Loughran S, Tennant N, Kishore A, Swan IR. Interobserver reliability in evaluating postural stability between clinicians and posturography. Clin Otolaryngol 2005; 30(3): 255-7. [Crossref]

12. Lin $Y, C$ Chen $T$, Tang $Y$, Wang C. A Reliability study for standing functional reach test using modified and traditional rulers. Percept Mot Skills 2012; II5(2): 512-20. [Crossref]

13. Balaban Ö, Nacır B, Erdem HR, Karagöz A. Denge fonksiyonunun değerlendirilmesi. J Phys Med Rehabil Sci 2009; 12: I33-9.

14. Black FO. Normal subject postural sway during the Romberg test. American journal of Otolaryngology 1982; 3(5): 309-18. [Crossref]
15. Bohannon RW, Larkin PA, Cook AC, Gear J et al. Decrease in timed balance test scores with aging. Physical therapy 1984; 64(7): 106770. [Crossref]

16. Shumway-Cook A, Horak FB. Assessing the influence of sensory interaction of balance. Suggestion from the field. Phys Ther 1986; 66 (I0): 1548-50. [Crossref]

17. Williams EN, Carroll SG, Reddihough DS, Phillips BA, Galea MP. Investigation of the timed 'up $\bar{\alpha}$ go'test in children. Dev Med Child Neurol 2005; 47(8): 518- 24. [Crossref]

18. Franjoine MR, Gunther JS, Taylor MJ. Pediatric Balance Scale: A Modified Version of the Berg Balance Scale for the School-Age Child with Mild to Moderate Motor Impairment. Pediatr Phys Ther 2003; 15(2): ||4-28. [Crossref]

19. Hazime FA, Allard P, Ide MR, Siqueira CM, Amorim CF, Tanaka C. Postural control under visual and proprioceptive perturbations during double and single limb stance. J Bodyw Mov Ther 2012; 16(2): 224-9. [Crossref]

20. Kayıhan H, Sade A, Cavlak U, Uysal G. Görme özürlü ve sağlıkı gençlerde denge ve dokunma algılanmasının karșılaștırılması. Fizyoterapi Rehabilitasyon 1989; 6(I): 63-75.

21. Pereira LM. Spatial concepts and balance performance: motor learning in blind and visually impaired children. Journal of visual impairment $\bar{\alpha}$ blindness 1990; 84(3): 109-II. [Crossref]

22. Kayıhan H. Görme özürlülerin rehabilitasyonu. Fizyoterapi ve Rehabilitasyonu Dergisi 1989; 6(I): 49-62.

23. Bouchard $D$, Tetreault $S$. The motor development of sighted children and children with moderate low vision aged 8-13. Journal of $\mathrm{Visual}$ Impairment反 Blindness 2000; 94(9): 564-73. [Crossref]

24. Murphy MF, O'driscoll M. Observation on the motor development of visually impaired children. Physiotherapy 1989; 75(9): 505-8. [Crossref] 